\title{
Oxidant Control of Polydopamine Surface Chemistry in Acids: a Mechanism- Based Entry to Superhydrophilic-Superoleophobic Coatings.
}

Florian Ponzio, Julien Barthes, Jérôme Bour, Marc Michel, Philippe Bertani, Joseph Hemmerlé, Marco d'Ischia and Vincent Ball*

\author{
Supporting Information
}

\section{Additional results}

\section{Structural analysis of $\mathrm{PDA}_{-\mathrm{NaIO}}$ and $\mathrm{PDA}_{4}$}

The peak at $177 \mathrm{ppm}$ observed in the ${ }^{13} \mathrm{C}$-MAS NMR spectra of the $\mathrm{PDA}-\mathrm{NaIO}_{4}$ films intensifies with an increase in the $\mathrm{NaIO}_{4}$ concentration and the same is observed for the appearance of the peak at around $20 \mathrm{ppm}$ which corresponds to an increase in the aliphatic chains content.

The UV-visible spectra of the PDA-NaIO $20 \mathrm{mM}$ films and of the dopamine-containing solutions analyzed after the same reaction time were not identical (Figure S10) especially at short reaction times. Taking into account possible differences between $\mathrm{PDA}^{-N_{a I O}}$ produced in solution and deposited on the substrate, the previous results were correlated to the XPS analysis of the PDA$\mathrm{NaIO}_{4}$ films produced at different oxidant concentrations. The total relative contents of all the elements present in the films $\left(\mathrm{C}, \mathrm{N}, \mathrm{O}, \mathrm{I}_{\text {from } \mathrm{IO}_{4}}{ }^{-}\right.$and $\mathrm{Si}$ from the silicon substrate) were used to plot the $\mathrm{O} / \mathrm{C}$ and the $\mathrm{N} / \mathrm{C}$ ratios, which are equal to 0.25 and 0.125 respectively for pure $\mathrm{PDA}-\mathrm{O}_{2}$. The analysis demonstrated that for the alkaline autoxidation process the $\mathrm{O} / \mathrm{C}$ and $\mathrm{N} / \mathrm{C}$ ratios were close to the expected values for PDA (Figure $2 \mathrm{~d}$ and S6). The iodine content of the PDA-NaIO films was increasing with the concentration of the oxidant used to deposit the films (Figure S8). Iodine is most probably present in the films in the form of $\mathrm{IO}_{3}{ }^{-}$anions, the reduced form of $\mathrm{IO}_{4}{ }^{-}$.

\section{Cytotoxic experiment by direct contact and Cell adhesion on $\mathrm{PDA}^{-N_{a I O}}$ films}

Cytotoxicity evaluation of the different PDA films prepared in the presence of either $\mathrm{O}_{2}$ or $\mathrm{NaIO}_{4}$ towards Balb 3T3 cells was performed at day 1, 3 and 6. Prior to cells seeding, the films were 
sterilized under UV irradiation for 15 minutes. Then Balb 3 T3 cells between passage 22 and 25 were seeded on top of each film ( 3 films for each condition) at a density of $1 \times 10^{5}$ cells/ film and the films were put in incubator for 15 minutes. After that, $1 \mathrm{~mL}$ of DMEM High Glucose culture medium (Dutscher, France) supplemented with penicillin/streptomycin $(1 \% \mathrm{v} / \mathrm{v})$ and FBS $(10 \% \mathrm{v} / \mathrm{v})$ were added in each well.

Metabolic activity was checked at day 1, 3 and 6 using Fluorimetric Cell Viability Kit (Promokine). $1 \mathrm{~mL}$ of resazurin solution $(10 \% \mathrm{v} / \mathrm{v}$ in supplemented DMEM High Glucose medium) was incubated $2 \mathrm{~h}$ in each well and then $3 \times 100 \mu \mathrm{L}$ of each supernatant was transferred in a 96 well plate for fluorescence reading. The fluorescence intensity of the solutions was monitored with a spectrofluorimeter (excitation at $\lambda=560 \mathrm{~nm}$ and mission at $\lambda=590 \mathrm{~nm}$ ). As a positive control, cells were cultivated on a glass slide (Figure S11).

Cell attachment of fibroblasts (NIH-3T3) was measured with a Horseradish Peroxidase (HRP) test. After $4 \mathrm{~h}$ of adhesion, the absorbance at $490 \mathrm{~nm}$ was equal to 2.7 for the PDA- $\mathrm{O}_{2}-2 \mathrm{~h}$ and to 2.8 for the PDA-NaIO $4-20 \mathrm{mM}-2 \mathrm{~h}$ films, indicating similar biocompatibility of both kinds of PDA films (Figure S12). 


\section{Additional figures}

Omin

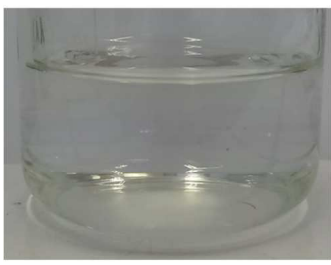

$15 \mathrm{~min}$

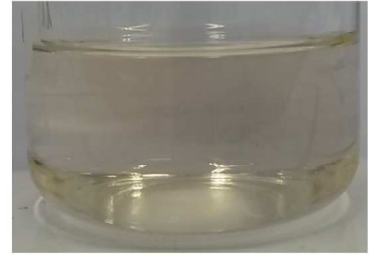

$300 \mathrm{~min}$

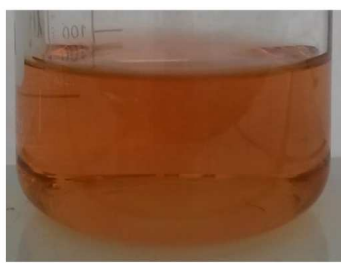

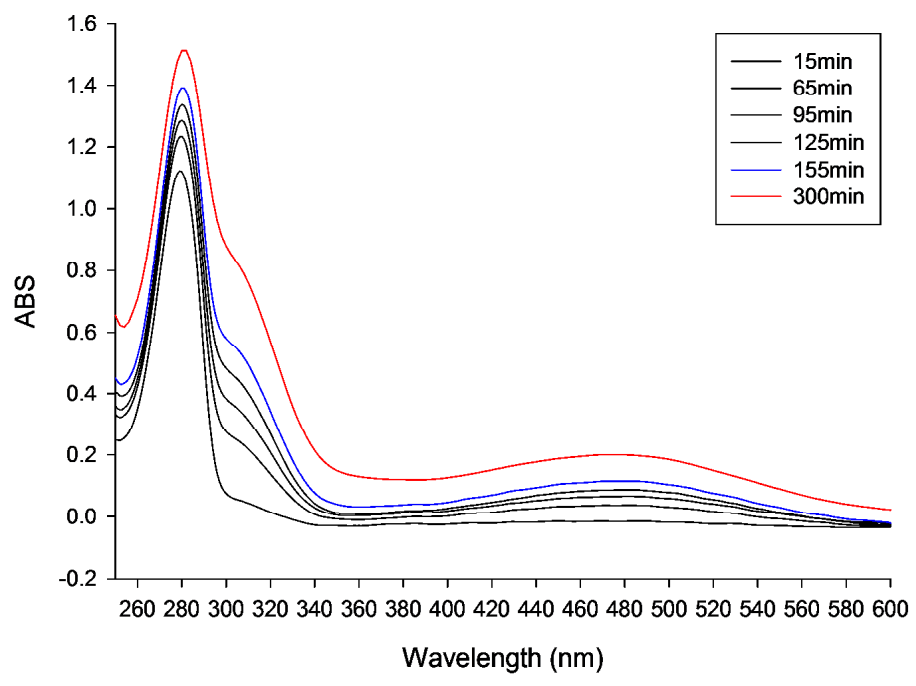

Figure S1: Evolution of the UV-vis spectra of dopamine solutions in the presence of $\mathrm{NaIO}_{3}$, the ratio between dopamine and the oxidant being $1 / 2$. The inset displays some digital pictures of the visual appearence of the solutions. 


\section{$24 \mathrm{H} \quad 5 \mathrm{H} \quad 2 \mathrm{H} \quad 0.5 \mathrm{H}$}

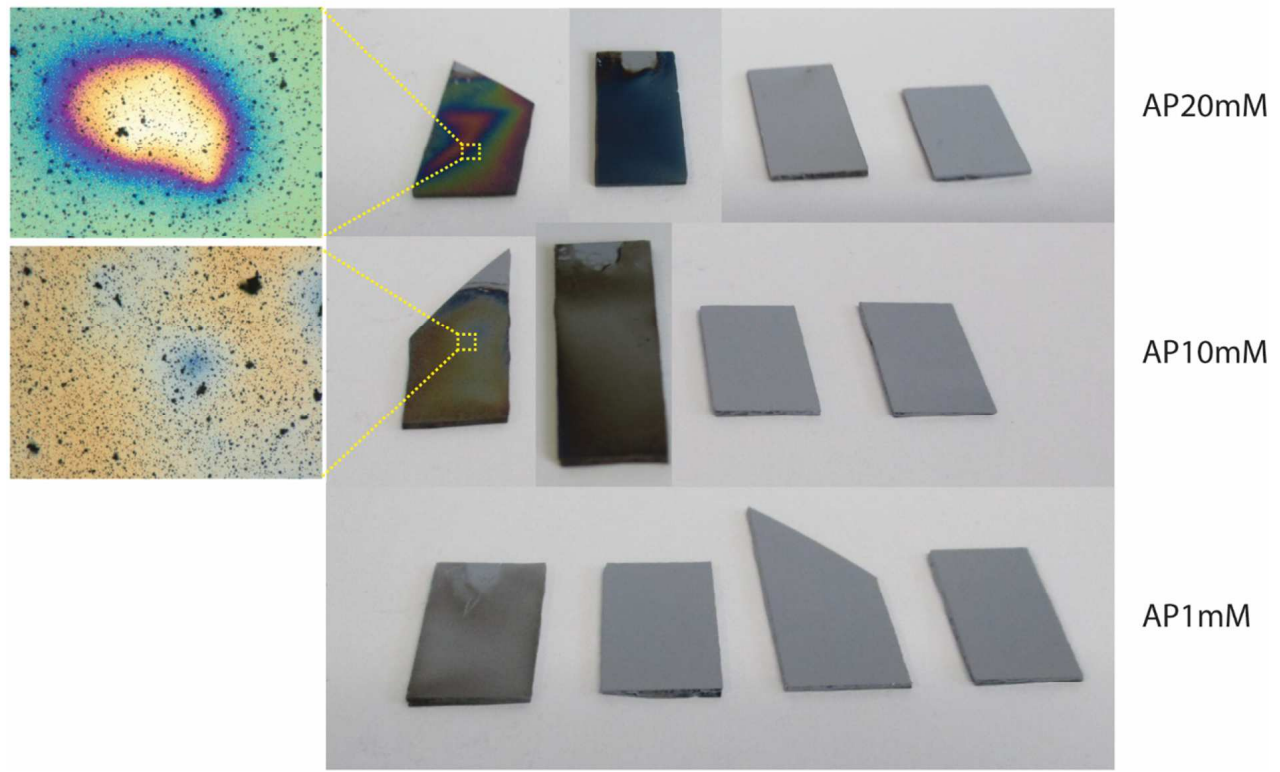

Figure S2: Digital pictures of PDA-AP films at 1, 10 and 20mM deposited on silicon wafers after $0.5,2,5$ and $24 \mathrm{~h}$ of reaction. Optical reflection microscopy zoom of the samples which are inhomogeneous. 


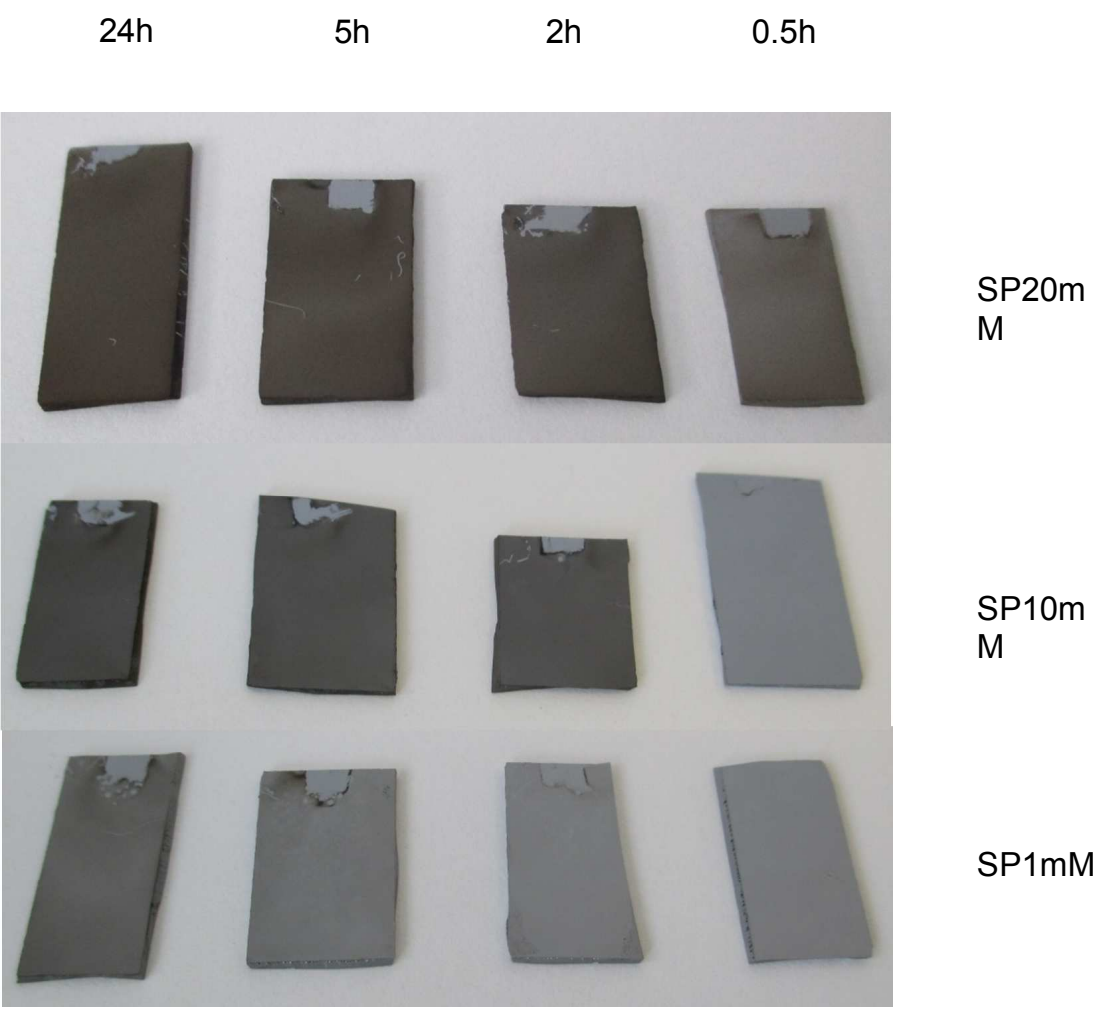

Figure S3: Digital pictures of PDA-SP films at 1, 10 and 20mM deposited on silicon wafers after $0.5,2,5$ and $24 \mathrm{~h}$ of reaction. 


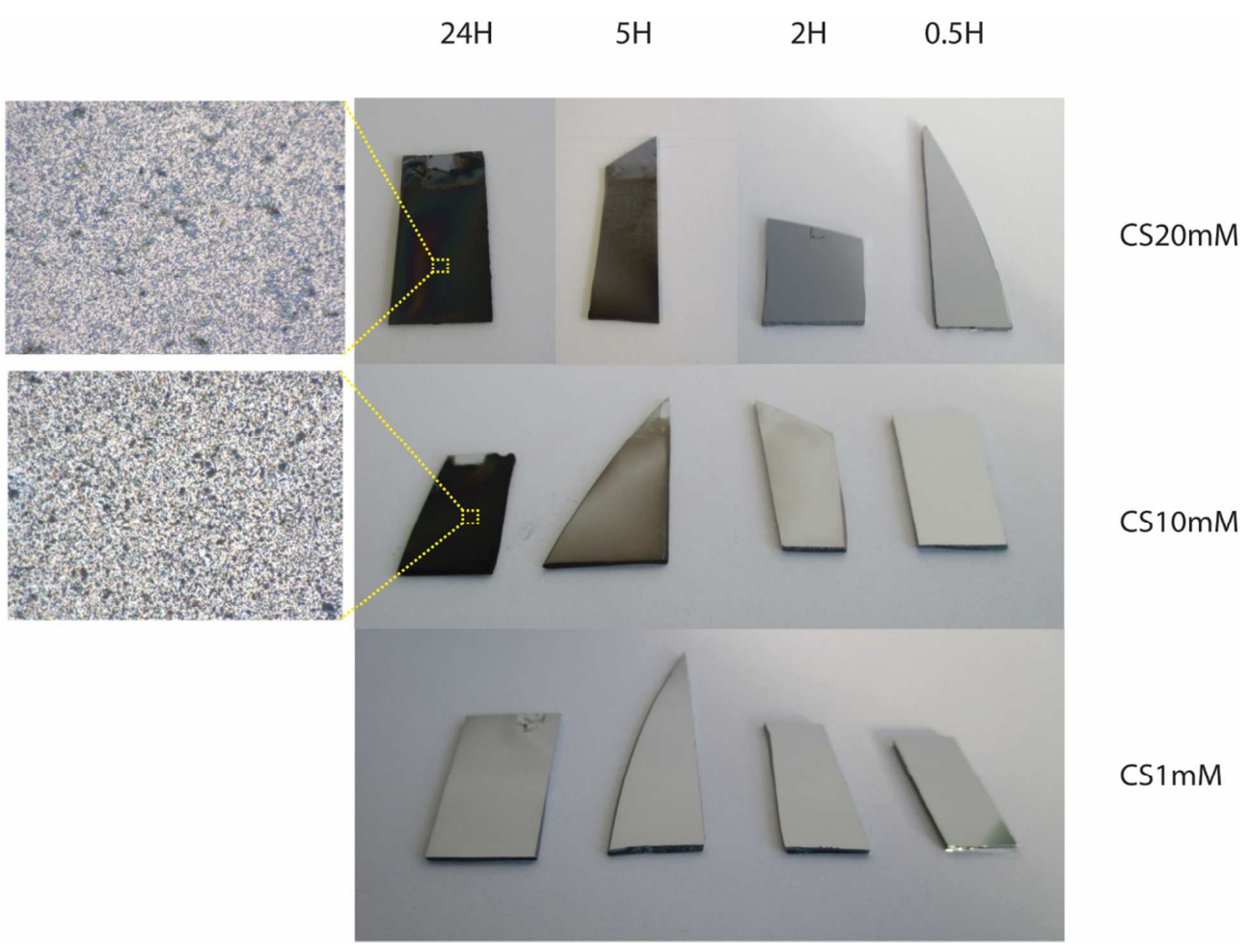

Figure S4: Digital pictures of PDA-CS films at 1, 10 and 20mM deposited on silicon wafers after $0.5,2,5$ and $24 \mathrm{~h}$ of reaction. Optical reflection microscopy zoom of the samples which are inhomogeneous. 


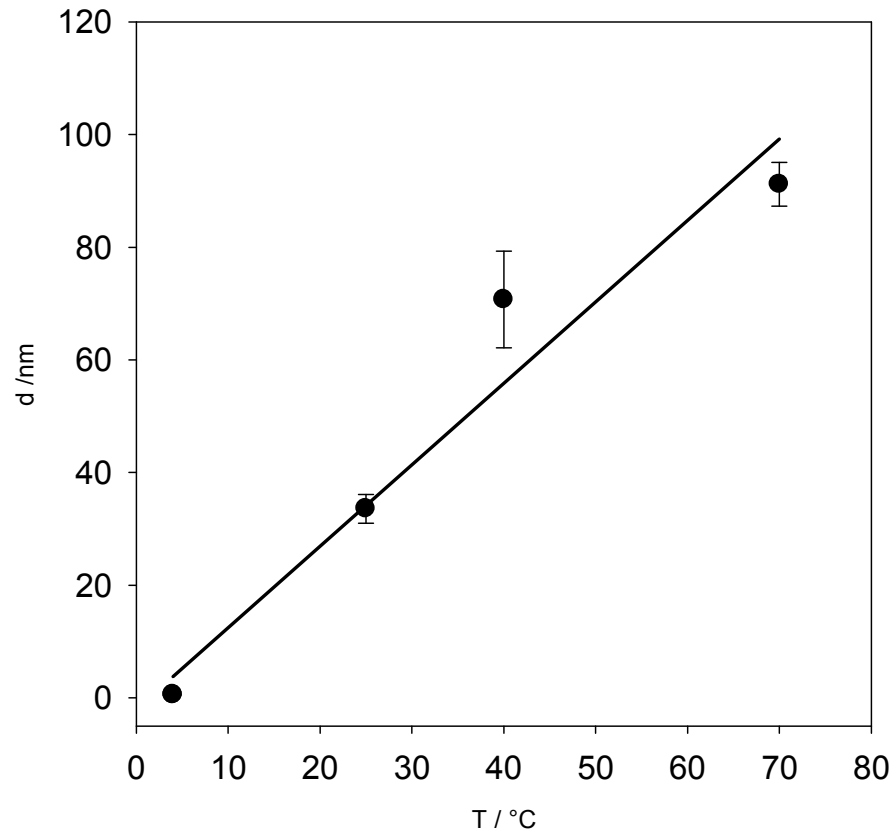

Figure S5: Temperature dependence of the thickness of PDA-SP films obtained in the presence of $10 \mathrm{mM} \mathrm{NaIO} 4(50 \mathrm{mM}$ sodium acetate buffer, $\mathrm{pH}=5.0)$ after $1 \mathrm{~h}$ hour of deposition on silicon wafers from $2 \mathrm{mg} \cdot \mathrm{mL}^{-1}$ dopamine solutions. The film thickness was measured by means of ellipsometry and the error bars correspond to one standard deviation over 5 measurement on each wafer. The slope of the straight line is equal to $1.45 \mathrm{~nm} \cdot \mathrm{K}^{-1}$. 


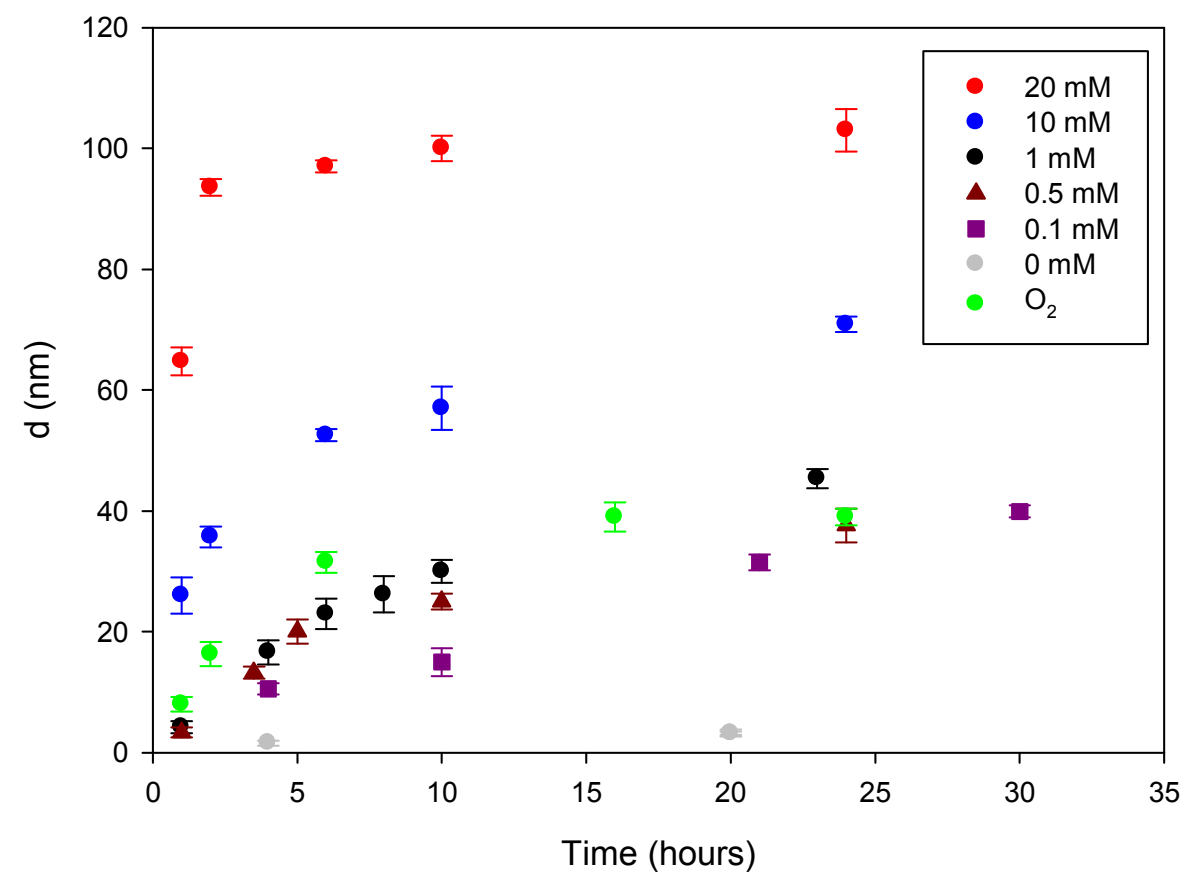

Figure S6: Thickness of PDA-SP and PDA-O $\mathrm{O}_{2}$ films deposited on silicon wafers as obtained by means of ellipsometry as a function of the reaction time and in the presence of $\mathrm{NaIO}_{4}$ at various concentrations: $\mathrm{O}_{2}(\bullet), 0 \mathrm{mM}(\bullet), 0.1 \mathrm{mM}(\boldsymbol{\bullet}), 0.5 \mathrm{mM}(\boldsymbol{\Delta}), 1 \mathrm{mM}(\bullet), 10 \mathrm{mM}(\bullet)$, and 20 $\mathrm{mM}(\bullet)$ in $\mathrm{NaIO}_{4}$. Each point corresponds to an individual experiment where the film was deposited on a freshly cleaned silicon wafer. The error bars correspond to one standard deviation of the film thickness calculated from 5 ellipsometry experiments on the same wafer. 


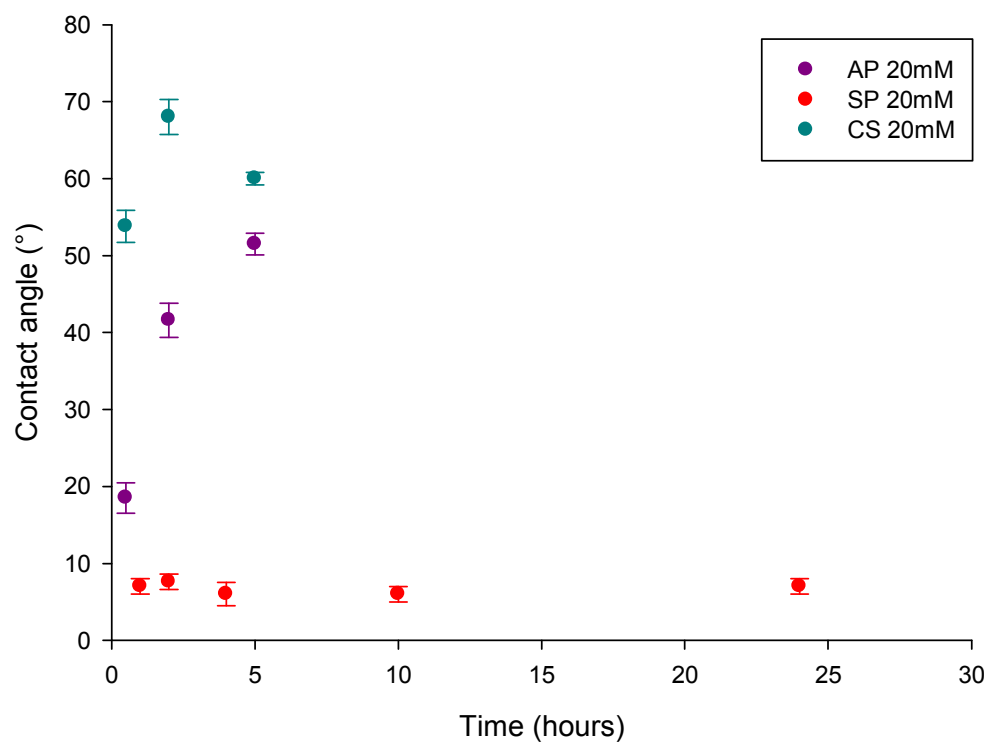

Figure S7: Comparison of the static water contact angles as a function of the PDA deposition time in the presence of the 3 used oxidants at a concentration of $20 \mathrm{mM}$. 
- Contact angle $\left({ }^{\circ}\right)$

- Thickness (nm)
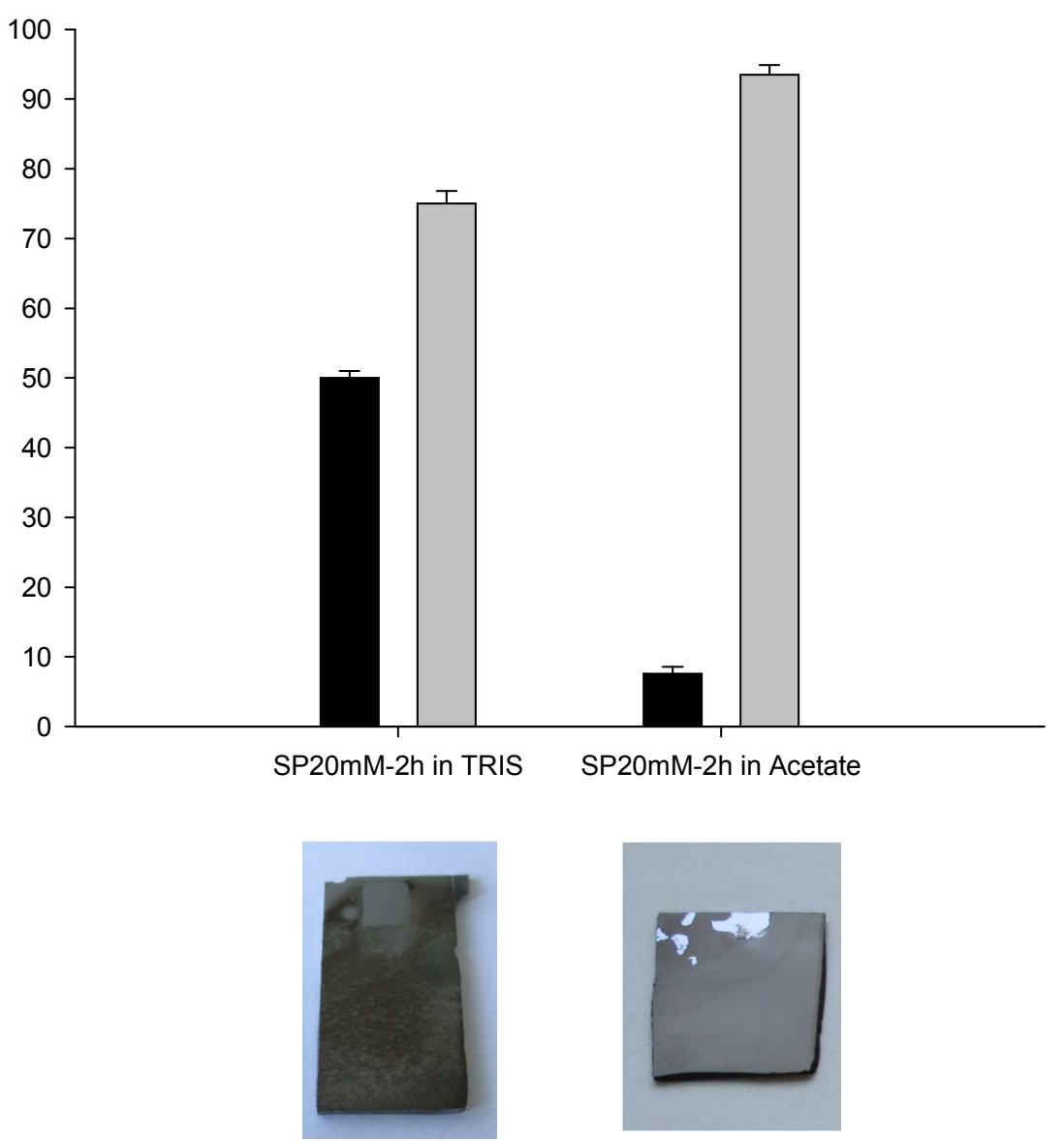

Figure S8: Comparison of the water contact angle, thickness and digital pictures for PDA-SP $20 \mathrm{mM}-2 \mathrm{~h}$ films (in Acetate buffer $\mathrm{pH}=5$ ) and for PDA-O $\mathrm{O}_{2}-2 \mathrm{~h}$ films (Tris buffer, $\mathrm{pH}=8.5$ ). 


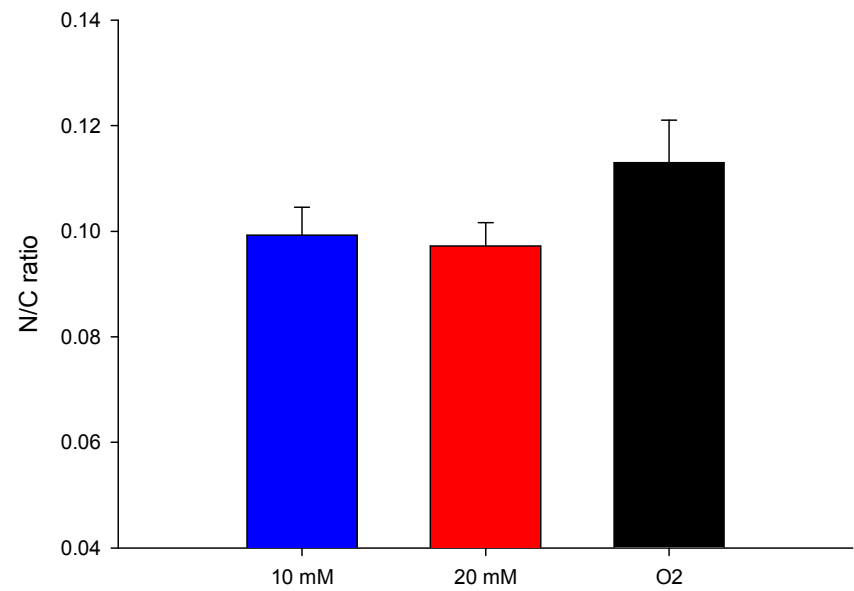

Figure S9: N/C ratios of the PDA-SP and of the PDA- $\mathrm{O}_{2}$ films obtained from $10.6 \mathrm{mM}$ dopamine solutions in the presence of $50 \mathrm{mM}$ Tris buffer at $\mathrm{pH}=8.5$ as obtained by XPS. The data correspond to the average on two different points for three different samples. 
A)

B)
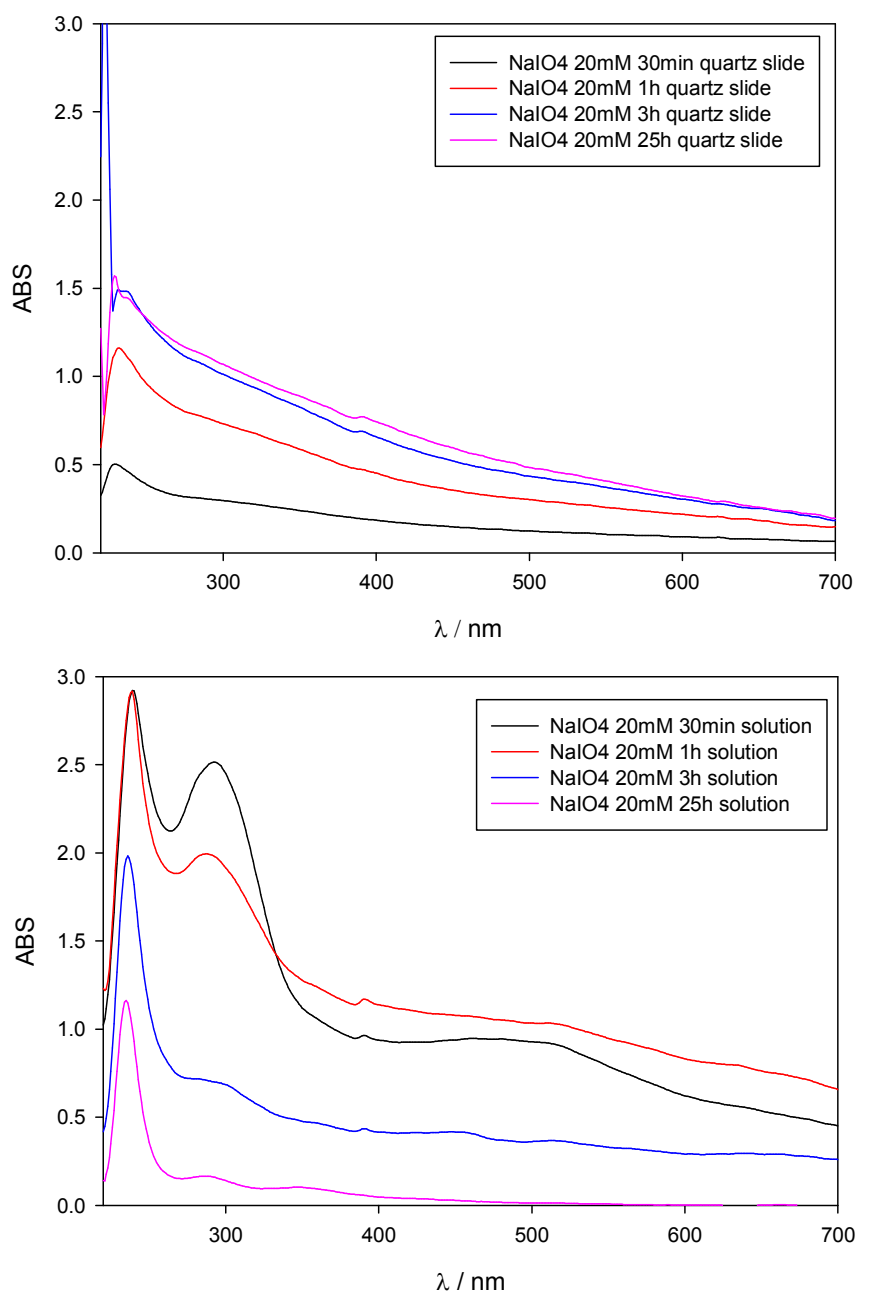

Figure S10: UV-Visible absorption spectra of PDA-SP-20mM films on a quartz slide A) and in solution B) after different reaction times. 


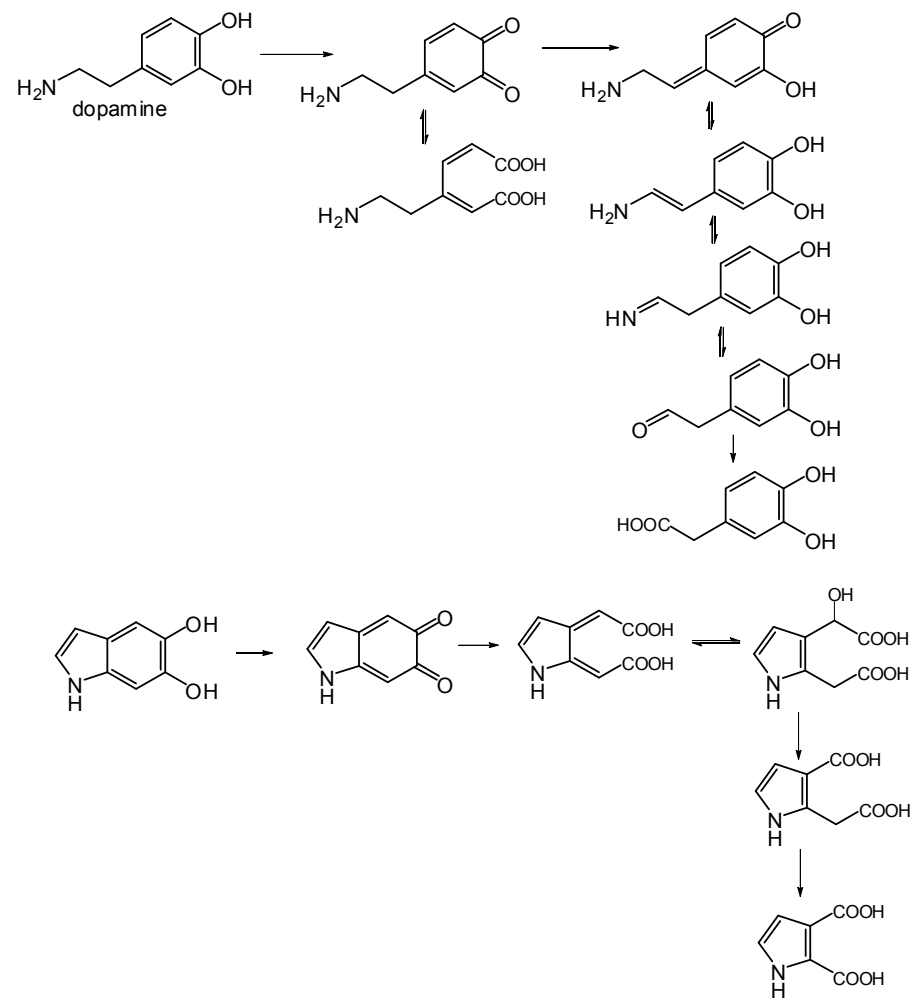

Figure S11: Schematic illustration of the quinone and side-chain breakdown pathways with nitrogen loss during the $\mathrm{NaIO}_{4}$ triggered oxidation of dopamine. 


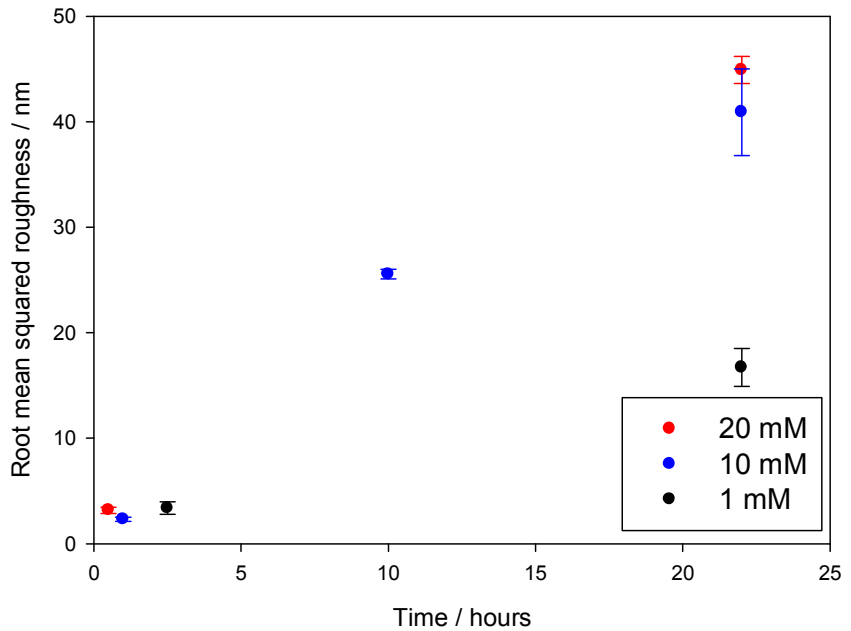

Figure S12: Evolution of the root mean squared roughness of PDA-SP films as a function of the reaction time in the presence of $1 \mathrm{mM}(\bullet), 10 \mathrm{mM}(\bullet)$, and $20 \mathrm{mM}(\bullet) \mathrm{NaIO}_{4}$. The dopamine concentration was of $10.6 \mathrm{mM}$. 
PDA-NalO $20 \mathrm{mM}$
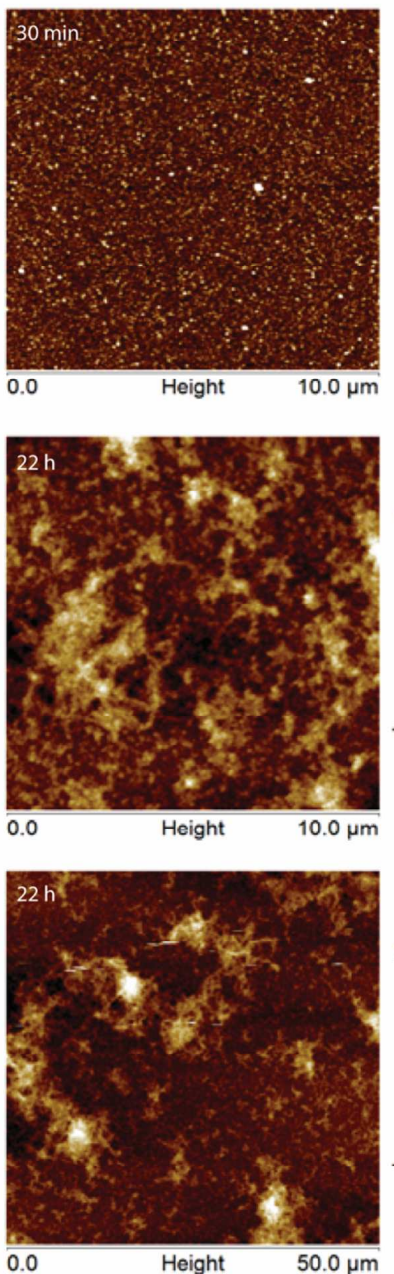

PDA-NalO $10 \mathrm{mM}$
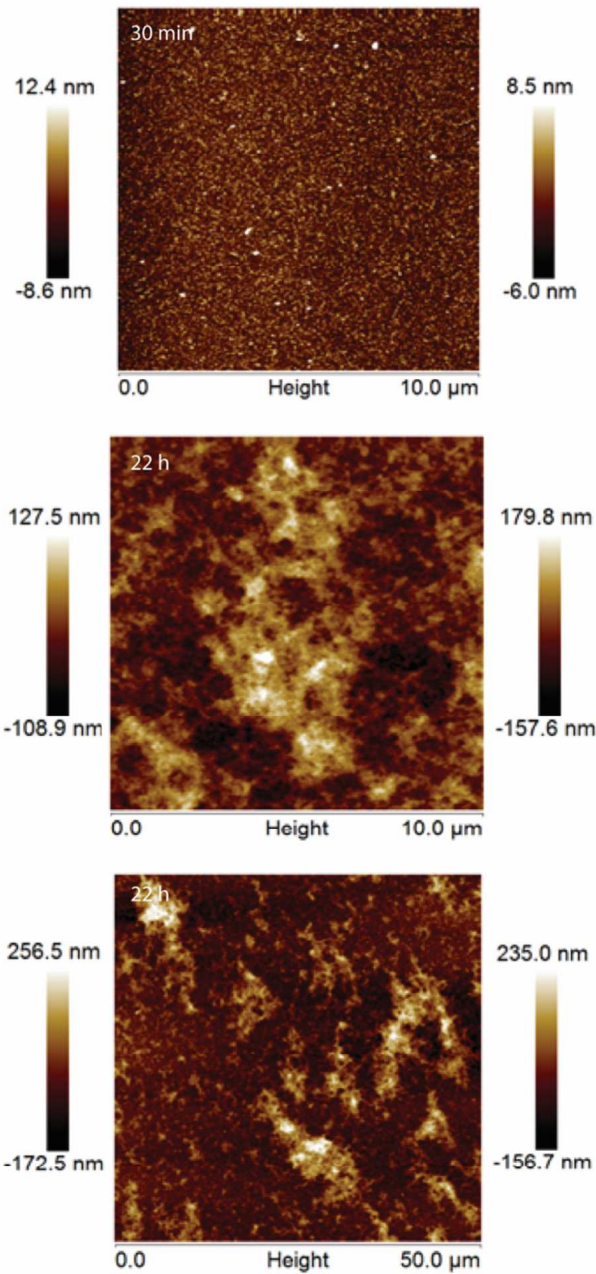

Figure S13: Surface topographies of PDA-SP films deposited on silicon wafers obtained from dopamine solutions at $10.6 \mathrm{mM}$ in the presence of $50 \mathrm{mM}$ sodium acetate buffer $(\mathrm{pH}=5.0)$ and in the presence of $10 \mathrm{mM}$ (right column) and $20 \mathrm{mM}$ (left column) $\mathrm{NaIO}_{4}$. The reaction time is indicated above each topography. 


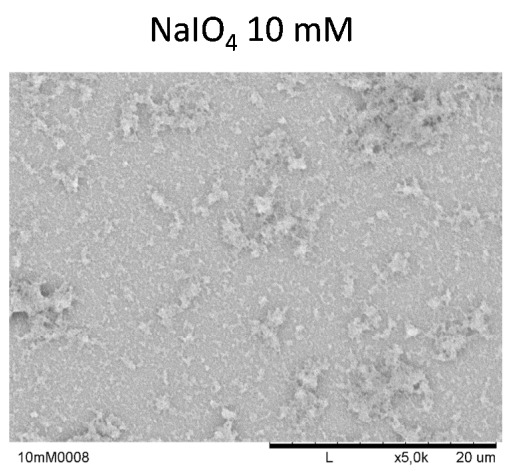

$\mathrm{NaIO}_{4} 30 \mathrm{mM}$

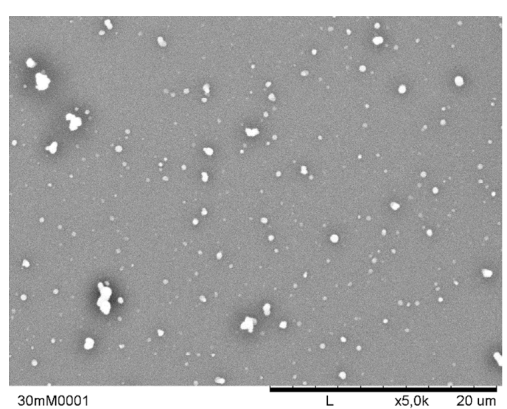

$\mathrm{NaIO}_{4} 20 \mathrm{mM}$

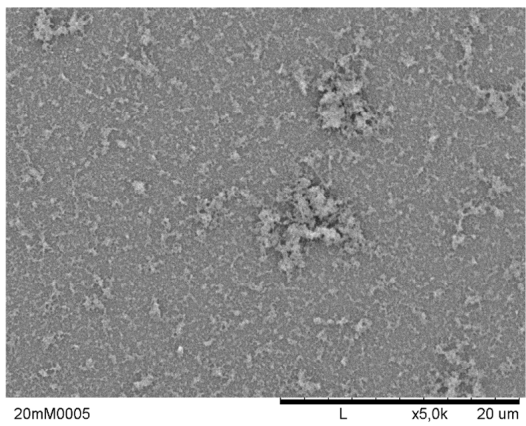

Tris $\mathrm{O}_{2}$

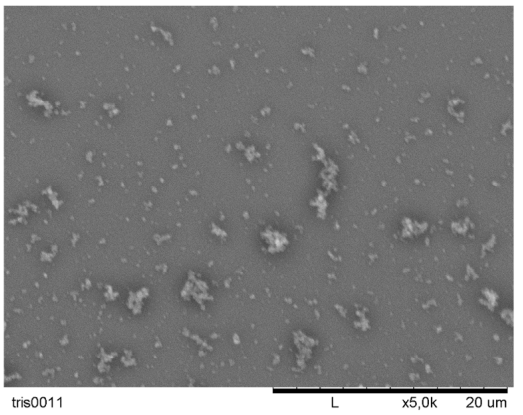

Figure S14: Scanning electron microscopy surface topography of PDA-SP films prepared in the presence of 10, 20, $30 \mathrm{mM} \mathrm{NaIO}_{4}$ and of PDA-O films after $24 \mathrm{~h}$ of deposition. 


\section{Silicium (Si) Polyethylene (PE)}

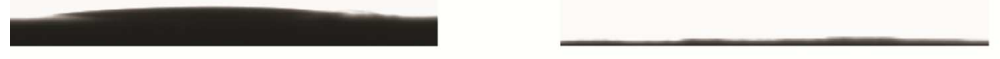

Polypropilene (PP) Polytetrafluoroethylene (PTFE)

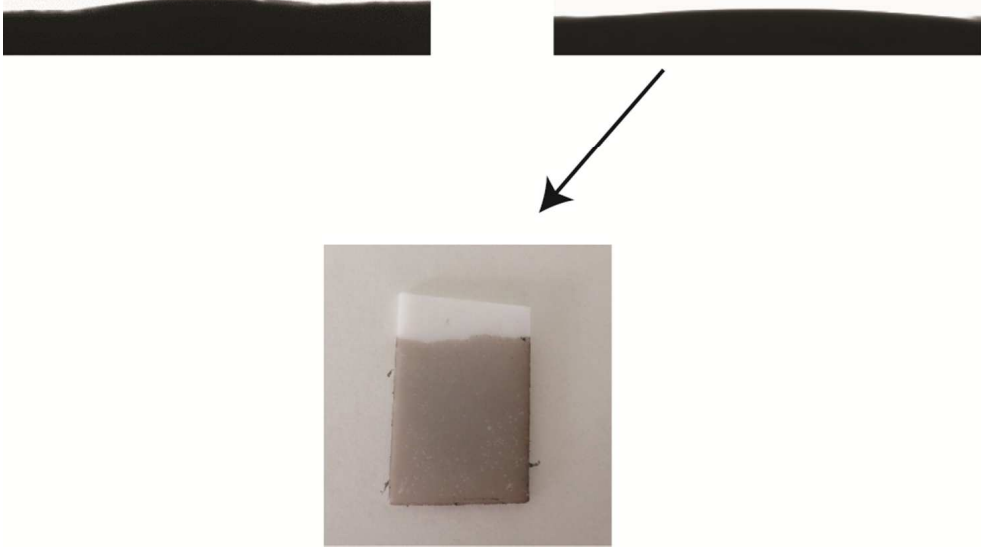

Figure S15: Static water contact angles on Si, PE, PP and PTFE coated with PDA-SP-10 mM during $2 \mathrm{~h}$. The picture represents the PTFE foil covered with a PDA-SP film on its lower part. 


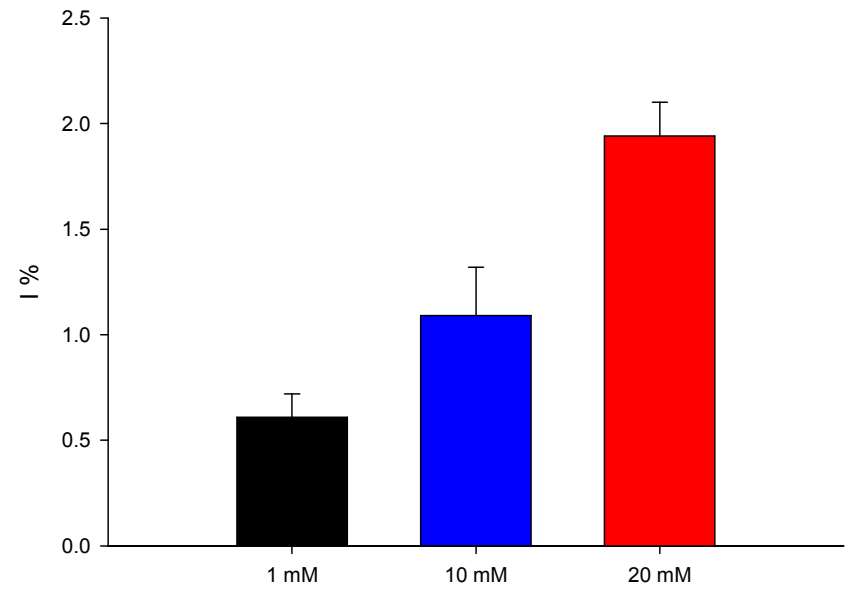

Figure S16: Variation of the iodine content of PDA-SP films as a function of the $\mathrm{NaIO}_{4}$ concentration after $24 \mathrm{~h}$ of film deposition. The data correspond to the average on two different points for three different samples as obtained by XPS. 


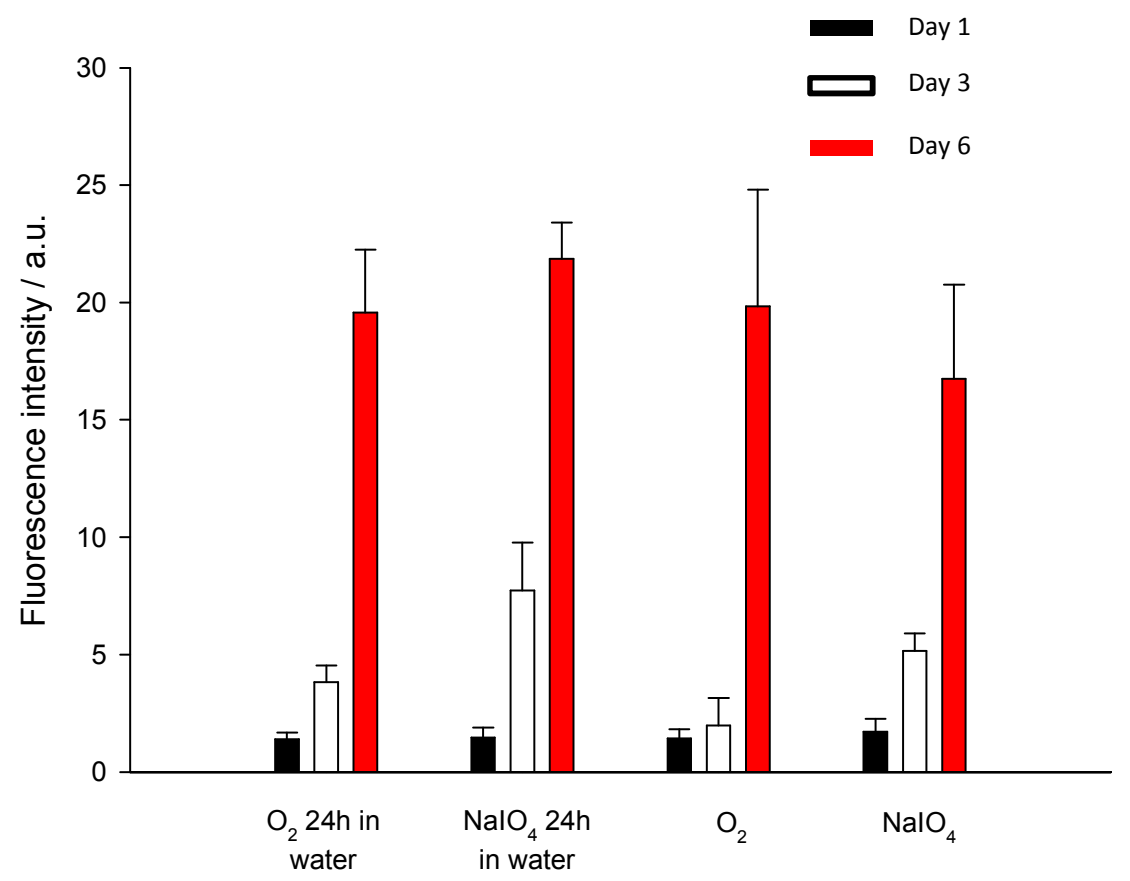

Figure S17: Direct contact cytotoxic tests on PDA-SP-20 mM-2h and PDA- ${ }_{2} 2 \mathrm{~h}$ films after 1, 3, and 6 days of contact with fibroblast cells. The cell viability was determined using cell metabolic activity test. 


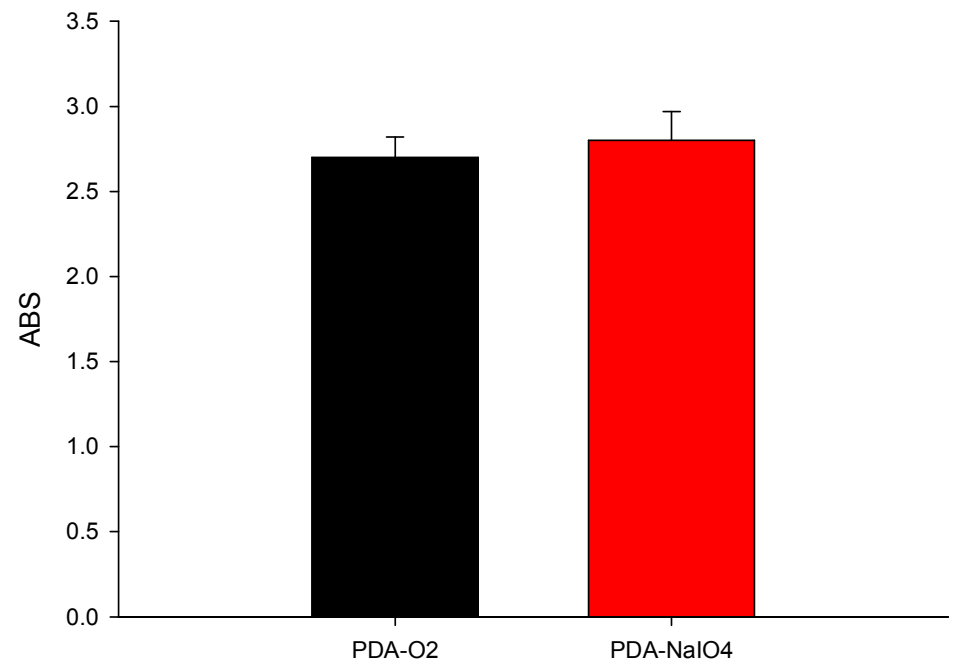

Figure S18: Absorbance values obtained after the HRP test for the PDA-SP20 mM-2h and PDA$\mathrm{O}_{2}-2 \mathrm{~h}$ films after $4 \mathrm{~h}$ of $3 \mathrm{~T} 3$ cell adhesion. 


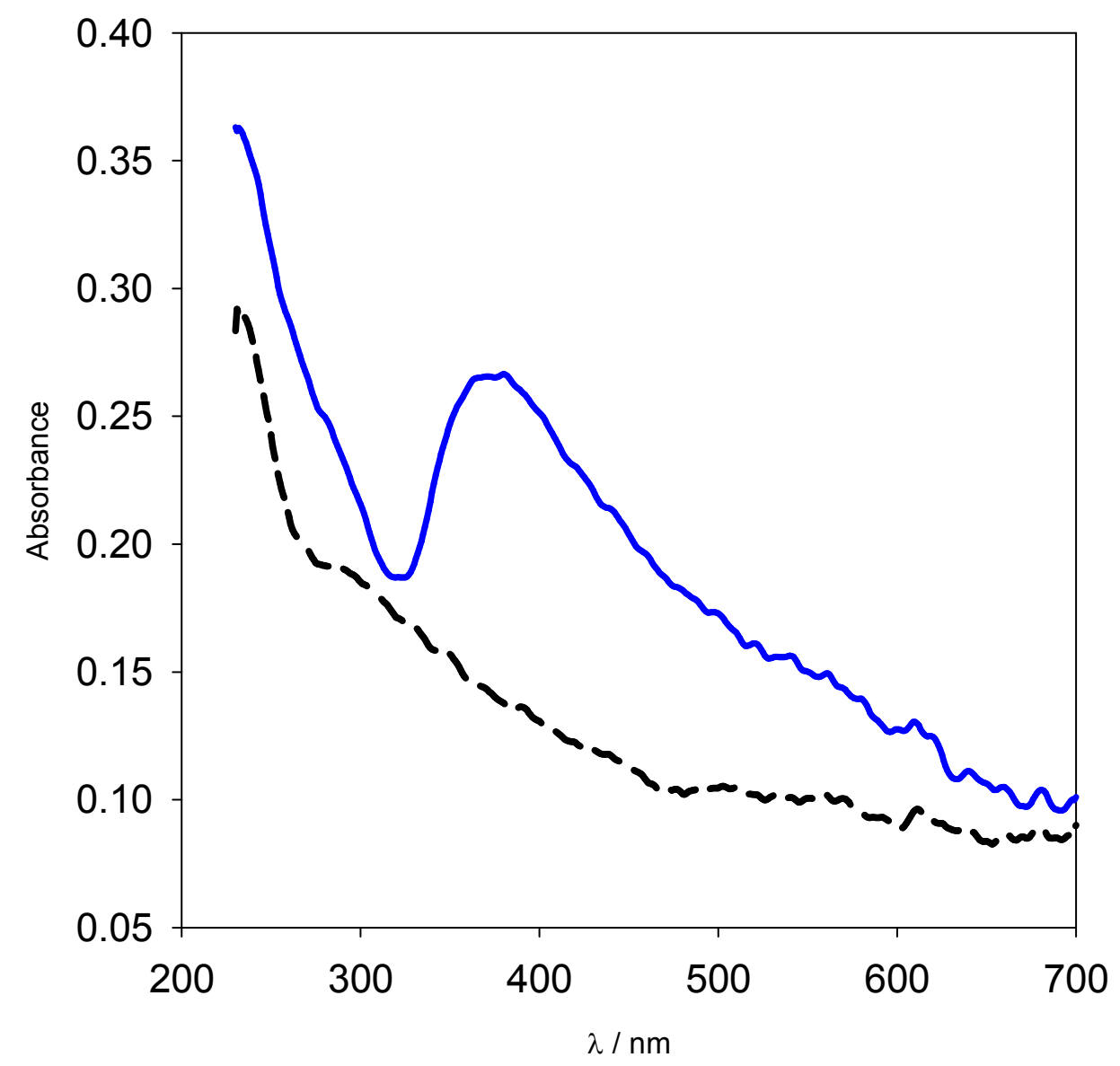

Figure S19: UV-vis spectra of a $\mathrm{PDA}_{-\mathrm{NaIO}_{4}} 10 \mathrm{mM}$ film after $1 \mathrm{~h}$ of dopamine oxidation (----) and after its exposure to a $10 \mathrm{mg} / \mathrm{mL} \mathrm{AgNO}_{3}$ aqueous solution during $15 \mathrm{~min}(-)$. 